\title{
PENGARUH PENGGUNAAN INTERNET TERHADAP PENGETAHUAN MAHASISWA TENTANG SISTEM INFORMASI AKADEMIK UNIVERSITAS DEHASEN BENGKULU \\ (Studi Pada Mahasiswa Program Studi Ilmu Komunikasi Angkatan 2011-2013)
}

Oleh:

\author{
NOFI AFRIANSYAH, LINDA ASTUTI, ASNAWATI \\ Prodi Ilmu Komunikasi Fakultas Ilmu-Ilmu Sosial UNIVED Bengkulu
}

\begin{abstract}
This study aims to investigate the effect of Internet use on students' knowledge on the Academic Information System (portal Siakad) Dehasen University of Bengkulu. Academic Portal is an information system that serves as an integrator of academic information among academic units, including providing academic information services for students. Unfortunately, not all students are able to operate Internet. The presence of portal Siakad assumed encourage students to learn to use the internet. This research is a descriptive quantitative survey. Primary data were collected by distributing questionnaires to 51 respondents who are students of Communication Department year 2011 to 2013 by using stratified random sampling technique. At the stage of analysis, data were tested by inferential statistical with product moment correlation formula, while hypothesis were tested by using $F$ $t$ test. The results showed the effect of Internet use on students' knowledge on Academic Information System at Dehasen University of Bengkulu, so that the working hypothesis (HK) is received. It means that, the more often students use the Internet to access the portal Siakad, the higher the student's knowledge of academic information.
\end{abstract}

\section{Keywords: Internet, Knowledge, Academic Information System}

\section{PENDAHULUAN}

Manusia selalu berusaha untuk memenuhi kebutuhan, termasuk kebutuhan informasi. Besarnya kebutuhan manusia akan informasi tersebut mendorong manusia menciptakan teknologi yang tepat dalam memberikan informasi, termasuk dalam dunia pendidikan tinggi. Universitas Dehasen telah menerapkan Sistem Informasi Akademik melalui Portal Siakad, sebagai sarana komunikasi antara Dosen, Mahasiswa dan Administrator yang berbasis web atau internet. Pemanfaatan teknologi informasi berbasis web ini sangat dibutuhkan untuk meningkatkan efisiensi dan produktivitas bagi manajemen pendidikan di perguruan tinggi.

Portal akademik merupakan sebuah sistem informasi yang berfungsi sebagai integrator informasi akademik (Jogiyanto, 2003), yang ada di berbagai unit akademik (program studi/fakultas/program) sekaligus sebagai sarana komunikasi antar civitas akademika kampus. Sistem ini dibangun dari kondisi eksistensi informasi akademik di kampus yang sangat beragam dan bervariasi bentuknya, sehingga membutuhkan sebuah "portal" yang akan mengintegrasikan informasi-informasi tersebut sehingga mempermudah diakses publik. Portal akademik dapat diakses melalui berbagai teknologi dan layanan. Pengguna Portal Akademik ini terdiri dari 3 jenis, yaitu; (a) administrator, (b) mahasiswa, dan (c) dosen. Sebuah portal akademik menawarkan antarmuka berbasis browser bagi pengguna dalam menyediakan akses ke informasi pribadi, sumber daya, dan aplikasi. Idealnya, portal akademik menghasilkan manfaat yang berbeda untuk kedua organisasi yaitu mahasiswa dan dosen, seperti mengurangi informasi yang berlebihan, mengurangi biaya organisasi, meningkatkan komunikasi 
universitas, dan meningkatkan produktivitas karyawan (dalam Tojib dkk, 2006: 40).

Universitas Dehasen Bengkulu telah menggunakan sistem informasi akademik dalam menunjang informasi yang dibutuhkan mahasiswa. Jurusan Ilmu Komunikasi di Fakultas Ilmu-Ilmu Sosial misalnya. Jurusan Ilmu Komunikasi telah memanfaatkan Sistem Informasi Akademik. Namun dalam pelaksanaannya, masih banyak mahasiswa tidak mengerti cara mengakses internet. Hal ini mengakibatkan kebingungan pada mahasiswa dalam mendapatkan informasi akademik yang sangat dibutuhkan seperti informasi mengenai pengurusan KRS, LHS dan informasi-informasi penting lainnya. Dilaksanakannya Sistem Informasi Akademik berbasis web oleh sebuah Universitas pada akhirnya mampu mendorong mahasiswa untuk meningkatkan pengetahuan tentang internet, manfaat serta cara menggunakannya. Berangkat dari fenomena dan permasalahan di atas, penelitian ini dilakukan untuk mengamati apakah ada pengaruh antara penggunaan internet terhadap pengetahuan mahasiswa jurusan Ilmu Komunikasi angkatan 20112013 tentang sistem informasi akademik dan seberapa besar pengaruh tersebut?

\section{METODE PENELITIAN}

Penelitian ini merupakan penelitian survei deskriptif kuantitatif. Data primer dilakukan dengan tiga cara, yaitu: observasi non-partisan, kuesioner, dan wawancara. Sedangkan data sekunder dilakukan melalui studi pustaka. Pengumpulan data dilakukan dengan menyebarkan kuesioner kepada responden yang dipilih secara acak. Menurut Masri Singarimbun (1993:3), penelitian survei adalah penelitian yang mengambil sampel suatu populasi dan menggunakan kuesioner sebagai alat pengumpul data pokok. Populasi pada penelitian ini adalah mahasiswa Fakultas Ilmu-Ilmu Sosial Jurusan Ilmu Komunikasi Universitas Dehasen Bengkulu angkatan 2011-2013 yang sedang aktif menjalani masa studi, tidak dalam keadaan cuti, maupun mahasiswa transfer (pindahan). Jumlah
Populasi pada penelitian ini adalah 105 orang dengan rincian; 60 orang dari angkatan 2011, 25 orang dari angkatan 2012, dan 20 orang angkatan 2013 (Sumber: Prodi Ilmu Komunikasi Unived, April 2015). Dari total populasi, tersebut sampel diambil berdasarkan metode acak terstratifikasi (stratified random sampling) dengan menggunakan rumus Taro Yamane (dalam Rakhmat, 1998:82) dengan presisi 10\% dan tingkat kepercayaan 90\%. Maka didapatkan sampel berdasarkan masing-masing angkatan sebagai berikut:

1. Mahasiswa ilmu komunikasi angkatan 2011 sebanyak 29 orang

2. Mahasiswa ilmu komunikasi angkatan 2012 sebanyak 12 orang

3. Mahasiswa ilmu komunikasi angkatan 2013 sebanyak 10 orang

Data yang diperoleh lalu dianalisis menggunakan pendekatan statistik deskriptif, yaitu sebagai berikut: Analisa Regresi Sederhana, Koefisien Korelasi Sederhana, Koefisien Determinasi, dan Uji Hitung (tTest).

\section{HASIL PENELITIAN DAN PEMBAHASAN \\ HASIL}

Data primer yang diperoleh melalui penyebaran kuesioner diolah kedalam bentuk interval serta dilakukan penyekoran. Dari penyebaran kuesioner kepada 51 orang responden, maka diperoleh tanggapan responden terhadap masing-masing variabel penelitian, yakni tanggapan dari variabel $\mathrm{X}$ yaitu Penggunaan Internet dan tanggapan variabel Y yaitu Pengetahuan Mahasiswa.

\section{Analisa Regresi Sederhana}

Adapun total skor hasil jawaban responden terhadap variabel $\mathrm{X}$ dan variabel $\mathrm{Y}$, maka diperoleh nilai-nilai tersebut seperti pada tabel berikut ini: 


\begin{tabular}{|c|c|c|}
\hline No & Keterangan & Kuantitas \\
\hline 1. & $\mathrm{~N}$ & 51 \\
\hline 2. & $\sum \mathrm{X}$ & 1971 \\
\hline 3. & $\sum \mathrm{Y}$ & 1983 \\
\hline 4. & $\sum \mathrm{X}^{2}$ & 77095 \\
\hline 5. & $\sum \mathrm{Y}^{2}$ & 78353 \\
\hline 6. & $\sum \mathrm{XY}$ & 77072 \\
\hline
\end{tabular}

Untuk melihat nilai yang diukur pada variabel yang diuji dalam pengaruh penggunaan internet terhadap pengetahuan mahasiswa tentang Sistem Informasi Akademik (Portal Siakad) Universitas Dehasen Bengkulu, peneliti menggunakan regresi sederhana, yaitu sebagai berikut:

$$
\mathrm{Y}=\mathrm{a}+\mathrm{bx}
$$

Untuk mencari nilai $\mathrm{b}$ adalah sebagai berikut:

$$
\begin{aligned}
\mathrm{b} & =\frac{\mathrm{N} \sum \mathrm{XY}-\sum X \sum Y}{N \sum X^{2}-\left(\sum X\right)^{2}} \\
& =\frac{51(77072)-(1971)(1983)}{51(77095)-(1971)^{2}} \\
& =\frac{3930672-3908493}{3931845-3884841} \\
& =\frac{22179}{47004} \\
& =0,471853459 \\
& =0,47
\end{aligned}
$$

Sedangkan, untuk mencari nilai a adalah sebagai berikut:

$$
\begin{aligned}
\mathrm{a} & =\frac{\sum \mathrm{Y}-\mathrm{b} \sum \mathrm{x}}{N} \\
& =\frac{1983-(0,47) 1971}{51} \\
& =\frac{1983-926,37}{51} \\
& =\frac{1056,63}{51} \\
& =20,71823529
\end{aligned}
$$

$$
=20,72
$$

Selanjutnya untuk nilai $\mathrm{Y}$ adalah sebagai berikut:

$$
\begin{aligned}
Y & =a+b(x) \\
& =0,47+20,72(x) \\
& =21,19(x)
\end{aligned}
$$

Jadi, nilai regresi sederhana (Y) adalah $21,19 \mathrm{x}$

\section{Koefisien Korelasi Sederhana}

Untuk mengetahui hubungan antara variabel bebas (penggunaan internet) dengan variabel terikat (Pengetahuan Mahasiswa) menggunakan analisis data Product moment yaitu mencari besar nilai $r$ (koefisien korelasi sederhana) yaitu sebagai berikut:

$$
\begin{aligned}
& r X Y=\frac{n \sum X Y-\left(\sum X\right)\left(\sum Y\right)}{\sqrt{\left.\ln \left(\sum X^{2}\right)-\left(\sum X\right)^{2}\right\}}\left\{n\left(\sum Y^{2}\right)-\left(\sum Y\right)^{2}\right\}} \\
& r X Y=\frac{51 x 77072-(1971)(1983)}{\sqrt{\left\{51(77095)-(1971)^{22}\right\}\left\{51(78353)-(1983)^{2}\right\}}} \\
& r X Y=\frac{3930672-3908493}{\sqrt{\{3931845-3884841\}}\{3996003-3932289\}}
\end{aligned}
$$

$r X Y=\frac{22179}{\sqrt{\{47004\}}\{63714\}}$

$$
r X Y=\frac{22179}{\sqrt{\{2994812856\}}}
$$

$$
r X Y=\frac{22179}{54724,88}
$$

$$
r X Y=0,405281838
$$

$r X Y=0,405$

Jadi, nilai korelasi (r) sebesar 0,405. 
Nilai $r \quad 0,405$ kemudian dikonsultasikan dengan $\mathrm{r}$ tabel product moment pada taraf $5 \%$ diperoleh $r$ tabel sebesar 0,271. Maka, dengan demikian dapat disimpulkan bahwa $r$ hitung sebesar $0,405>r$ tabel sebesar 0,271. Hal ini membuktikan bahwa hipotesis kerja (HK) diterima yaitu Pengaruh Penggunaan Internet Terhadap Pengetahuan Mahasiswa tentang Sistem Informasi Akademik Universitas Dehasen, artinya semakin sering mahasiswa menggunakan internet dalam mengakses Portal Siakad, maka semakin meningkat pengetahuan mahasiswa tentang informasi akademik.

\section{Koefisien Determinasi (Kd)}

Selanjutnya, untuk mengetahui seberapa besar persentase pengaruh hubungan antara variabel $\mathrm{X}$ dan Variabel $Y$ menggunakan rumus koefisien determinasi sebagai berikut:

$$
\begin{aligned}
K d & =r^{2} \times 100 \% \\
K d & =0,405^{2} \times 100 \% \\
K d & =0,164025 \times 100 \% \\
K d & =16,40 \%
\end{aligned}
$$

Berdasarkan hasil penghitungan koefisien determinasi tersebut dapat disimpulkan bahwa hubungan antara variabel $\mathrm{X}$ dengan variabel $\mathrm{Y}$ didapatkan hasil Kd sebesar 16,40\%. Jadi, besarnya pengaruh penggunaan internet terhadap pengetahuan mahasiswa tentang sistem informasi akademik Universitas Dehasen hanya sebesar $16,40 \%$. Artinya ada faktor lain di luar variabel yang diteliti yang mempengaruhi penggunaan internet di kalangan mahasiswa $83,60 \%$.

\section{Pengujian Hipotesis}

Untuk mengetahui dan membuktikan adanya pengaruh signifikan dalam penggunaan internet terhadap
pengetahuan mahasiswa tentang sistem informasi akademik Universitas Dehasen, dilakukan perhitungan dengan Formulasi t-test, sebagai berikut:

$$
\begin{aligned}
& F-t \text { test }=\frac{y^{2}}{1,-y^{2}}(N-2) \\
& F-t \text { test }=\frac{0,405^{2}}{1,-0,405^{2}}(51-2) \\
& F-t \text { test }=\frac{0,16}{1-0,16}(49) \\
& F-t \text { test }=\frac{0,16}{0,84}(49) \\
& F-t \text { test }=0,19 x(49) \\
& F-t \text { test }=9,31
\end{aligned}
$$

Jadi, F t-hitung ( $\mathrm{t}$ test) sebesar 9,31

Untuk menguji hipotesis maka harus dilakukan penghitungan $t$ tabel pada taraf signifikansi 5\% didapatkan dengan rumus sebagai berikut:

Df1 = $\mathrm{k}-1$ ( $\mathrm{k}$ adalah jumlah variabel $\mathrm{x}+$ jumlah variabel $\mathrm{y}$ )

$=2-1$

$=1$

Df2 $=\mathrm{N}-\mathrm{k}(\mathrm{N}$ jumlah responden $)$

$=51-1$

$=50$

Maka, didapatkan $\mathrm{t}$ tabel sebesar 4,03 .

Berdasarkan hasil hitung $\mathrm{F}$ t-hitung didapatkan hasil sebesar 9,31 dan dikonsultasikan dengan t-tabel dengan signifikansi $5 \%$ diperoleh $\mathrm{t}$ tabel sebesar 4,03. Dengan demikian t-hitung sebesar 9,31>t-tabel sebesar 
4,03. Hal ini membuktikan adanya hubungan antarvariabel, dengan demikian Ho ditolak dan Hipotesis Kerja (HK) diterima, yaitu ada pengaruh antara penggunaan internet terhadap pengetahuan mahasiswa tentang sistem informasi akademik (Portal Siakad) Universitas Dehasen, artinya semakin sering mahasiswa menggunakan internet dalam mengakses Portal Siakad, semakin tinggi pengetahuan informasi akademik mahasiswa.

\section{Pembahasan}

Pada konteks penelitian ini berdasarkan teori Uses and Gratification yang meneliti tentang kebutuhan manusia baik secara psikis maupun sosial, pengguna media memainkan peran dalam menggunakan media guna memenuhi kebutuhannya. Pengguna media akan berusaha untuk mencari sumber media sebagai pemuas kebutuhannya.

Mahasiswa ilmu komunikasi memiliki kebutuhan secara psikologi dan sosial untuk memenuhi kebutuhan akan informasi akademik sebagai salah satu aktivitas di perguruan tinggi. Untuk mendapatkan informasi akademik, perguruan tinggi telah memberikan wadah sistem informasi sebagai integrator informasi akademik melalui Portal Siakad baik bagi program studi, fakultas, maupun seluruh civitas akademika kampus. Sebagai salah satu user (pengguna) mahasiswa komunikasi telah memanfaatkan Portal Siakad untuk memenuhi kebutuhan akan informasi akademik. Informasi yang dibutuhkan oleh mahasiswa Ilmu Komunikasi seperti Kartu hasil Studi (KHS), transkrip nilai, dan sebagainya mahasiswa diharuskan memahami dan mampu menggunakan internet. Berdasarkan karakteristik responden, diketahui bahwa mahasiswa yang tidak dapat mengoperasikan internet dikarenakan faktor usia mereka yang sudah tinggi, dan disebabkan oleh kesibukan pekerjaan yang mereka lakukan. Keberadaan sistem informasi akademik yang berbasis web telah mengharuskan mahasiswa untuk bisa mengoperasikan internet, sebab untuk mendapatkan nilai (KHS), mengurus kartu rencana studi (KRS) sudah dilakukan melalui Portal Siakad. Adanya Sistem Informasi Akademik melalui internet telah memberikan pengaruh yang signifikan kepada mahasiswa untuk mempelajari teknologi internet. Hal tersebut secara langsung mampu meningkatkan pengetahuan mahasiswa, baik dalam informasi akademik, teknologi internet dan sebagainya.

Selanjutnya, pengaruh penggunaan internet telah meningkatkan pengetahuan mahasiswa dalam mendapatkan informasi akademik. Dengan kata lain, portal Siakad telah memberikan kemudahan bagi mahasiswa. Hal ini dikarenakan sebelum adanya Portal Siakad, untuk mendapatkan informasi akademik mahasiswa Ilmu Komunikasi harus mendatangi kampus dan bertanya kepada petugas. Informasi akademik yang diperoleh dengan mendatangi kampus tentunya tidak efisien bagi mahasiswa sebab dengan berbagai aktivitas mahasiswa dan lokasi tempat tinggal yang jauh dengan kampus memberikan kesulitan untuk memenuhi informasi akademik, apalagi tidak sedikit mahasiswa yang bertempat tinggal di luar kota Bengkulu. Kehadiran Portal Siakad telah memberikan kemudahan bagi mahasiswa. Meskipun sebelumnya ada beberapa mahasiswa belum begitu paham internet, bahkan ada yang tidak bisa mengoperasikan internet, adanya Sistem Informasi Akademik (Portal Siakad) telah mendorong mahasiswa untuk belajar memahami dan mengoperasikan internet seperti yang disampaikan oleh salah satu mahasiswa Yogi (nama samaran) 33 tahun, mahasiswa Ilmu Komunikasi angkatan 2011 berikut ini:

\footnotetext{
"Saya sih, tidak begitu mengerti internet...yaa kalau dengar-dengar internet, yaa sering..cuma untuk menjalankan internet saya memang belum bisa. Adanya Portal Siakad Dehasen awalnya memberikan kebingungan bagi saya..saya kan belum bisa menjalankan internet, namun dikarenakan mau lihat nilai melalui internet mau tidak mau saya harus belajar... tidak kursus mas, cuma belajar
} 
dengan teman-teman kuliah.. sekarang saya sudah bisa internet mas, ternyata Portal Siakad memberikan kemudahan dalam mendapatkan informasi, saya merasa senang mas, jadi saya tidak perlu capek-capek ke kampus, maklumlah rumah dan kampus saya sangat jauh mas" (Sumber: Penelitian, April 2015).

Berdasarkan keterangan Yogi, dapat dikatakan bahwa Portal Siakad telah membuatnya senang karena akhirnya ia mampu mengoperasikan. Hal ini tentunya telah meningkatkan pengetahuan Yogi baik pengetahuan tentang internet, maupun pemenuhan informasi yang ia butuhkan.

\section{PENUTUP}

\section{Kesimpulan}

Berdasarkan hasil perhitungan dan pembahasan dapat disimpulkan bahwa ada pengaruh penggunaan internet terhadap pengetahuan mahasiswa tentang Sistem Informasi Akademik Universitas Dehasen Bengkulu, sehingga hipotesis kerja (HK) diterima. Artinya, semakin sering mahasiswa menggunakan internet dalam mengakses Portal Siakad, maka semakin tinggi pengetahuan mahasiswa tentang informasi akademik. Hal ini dapat dilihat dari hasil perhitungan $\mathrm{r}$ dengan product moment didapatkan $r$ hitung sebesar 0,405 lebih besar dari $r$ tabel sebesar 0,271. Selanjutnya, uji hipotesis menunjukan bahwa t hitung sebesar 9,31 lebih besar dari t tabel sebesar 4,03 hal ini membuktikan bahwa signifikasi hubungan pengaruh penggunaan internet terhadap pengetahuan mahasiswa yang terjadi sangat erat.

Sementara itu, besarnya koefisien determinasi $16,40 \%$ menunjukan besarnya pengaruh penggunaan internet terhadap pengetahuan mahasiswa tentang Sistem Informasi Akademik Universitas Dehasen hanya $16,40 \%$, ada faktor lain yang juga memiliki pengaruh penggunaan internet tersebut sebesar $83,60 \%$ di luar variabel yang diteliti.

\section{Saran}

Berdasarkan hasil penelitian, peneliti mengajukan saran sebagai berikut:

1. Untuk pihak Portal Siakad Universitas Dehasen hendaknya selalu meningkatkan kualitas pelayanan, memperbaiki sistem jaringan, serta menambahkan berbagai macam rubrik menarik untuk lebih memberikan kepuasan bagi pengguna internet, khususnya mahasiswa Universitas Dehasen Bengkulu.

2. Untuk mahasiswa Ilmu Komunikasi agar lebih memanfaatkan Sistem Informasi Akademik (Portal Siakad) Universitas Dehasen Bengkulu untuk menunjang kegiatan akademik.

3. Untuk Peneliti selanjutnya, perlu mengkaji lebih mendalam tentang penggunaan internet terhadap pengetahuan mahasiswa tentang Sistem Informasi Akademik (Portal Siakad) Universitas Dehasen Bengkulu dengan variabel-variabel lain seperti motif penggunaan internet, hubungan dan lain-lain.

\section{DAFTAR PUSTAKA}

Jogiyanto. (2003). "Sistem Teknologi Informasi, Pendekatan terintegrasi: Konsep Dasar Teknologi, Aplikasi, Pengembangan dan Pengelolaan". Yogyakarta: Andi Offset.

McQuail, Denis. (1991). "Teori Komunikasi Massa”. Jakarta: Erlangga

Prasetyo, Bambang dan Lina Miftahul Jannah. (2010). "Metode Penelitian Kuantitatif: Teori dan Aplikasi”. Jakarta: PT. Raja Grafindo Persada.

Rakhmat, Jalalludin. (1998). "Metodologi Penelitian Komunikasi". Bandung: PT. Remaja Rosdakarya. 
Samzy, Robert. (2013). "Hubungan Ketersediaan Layanan Hotspot Kampus dengan Civitas Akademika Universitas Bengkulu”. Skripsi Fakultas Ilmu Sosial dan Ilmu Politik Universitas Bengkulu.

Santoso, Budi. (2008). "Pemanfaatan Internet oleh Pengguna Perpustakaan Mahasiswa Fakultas
Kedokteran UGM Yogyakarta”. http://digilib.uinsuka.ac.id/gdl.php?mod=browse\&o p-read\&id=digilib-uinsuka-budhisanto-806

Singarimbun, Masri dan Effendi, Sofian. (1999). "Metode Penelitian Survai". Jakarta: LP3ES. 